\title{
Espacio y territorio como categorías para la comprensión del tiempo presente: emergencia teórica y renovación conceptual a propósito del octubre chileno - 2019
}

\author{
Space and Territory as Categories for Understanding the Present Time: \\ Theoretical Emergence and Conceptual Renewal Regarding the \\ Chilean October - 2019
}

\section{Carla Marchant Santiago*; Yerko Monje-Hernández ${ }^{* *}$}

*Instituto de Ciencias Ambientales y Evolutivas, Universidad Austral de Chile Laboratorio de Estudios Territoriales UACh - Núcleo de Estudios Interdisciplinarios en torno a la Desigualdad y Derechos Humanos UACh carla.marchant@uach.cl

${ }^{* *}$ Instituto de Historia y Ciencias Sociales, Universidad Austral de Chile Laboratorio de Estudios Territoriales UACh - Núcleo de Estudios Interdisciplinarios en torno a la Desigualdad y Derechos Humanos UACh yerko.monje@uach.cl

\section{Resumen}

El ciclo de movilización iniciado en octubre de 2019 representó un momento crucial en la trayectoria democrática chilena. Lo que se inició como una protesta por el alza de 30 pesos chilenos en el Metro de Santiago, rápidamente tomó tintes de movimiento nacional, cuando las demandas puntuales se transformaron en una crítica sistémica y estructural de la conformación democrática, constitucional, política, económica, social y cultural heredada desde la dictadura. Este despertar social de octubre, no solo implicó transformaciones asociadas al plano de la vida material, sino también cambios en torno a las herramientas conceptuales y teóricas que son utilizadas para la comprensión de los fenómenos sociales desde los espacios de ejercicio intelectual, como las universidades. Ejemplos de esas categorías son precisamente el espacio y territorio, conceptos que a partir de la década del noventa,

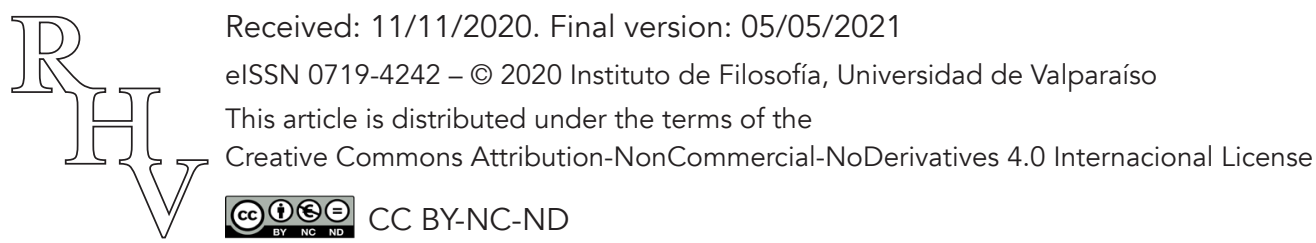


Espacio y territorio como categorías para la comprensión del tiempo presente...

Carla Marchant Santiago; Yerko Monje-Hernández

con sostenidos y crecientes movimientos socioambientales, se instalaron en el repertorio de demandas populares, vislumbrando con fuerza una de las consignas de las protestas de octubre: la defensa de los territorios como espacios para la vida. A partir de ello, se propone un recorrido en dos dimensiones; primero un debate conceptual teórico desde la tradición geográfica y, por otro lado, una aproximación histórica de la emergencia de la categoría en la historia reciente chilena, con el interés de comprender una dimensión socio-territorial e histórica de lo acontecido en octubre de 2019.

Palabras Claves: geografía, historiografía, interdisciplinariedad, sociedad, naturaleza.

\begin{abstract}
The mobilization cycle that began in October 2019 represented a crucial moment in the Chilean democratic trajectory. What began as a protest for the rise of $30 \mathrm{Chi}$ lean pesos in the Santiago Metro, quickly took on national demand as the horizon exceeded that specific bid, and became a systemic and structural criticism of the democratic institutions and the constitutional, economic, social and cultural structure inherited from the dictatorship. This social awakening in October not only implied transformations associated to material life. Also the conceptual and theoretical tools that were used to understand social phenomena from spaces of intellectual exercise, such as universities were modified. One of these categories is precisely space and territory, which from the nineties with supported and growing socio-environmental movements, was installed in the repertoire of popular demands. A dimension that was also strongly glimpsed in the October protests: the defence of territories as spaces for life. Based on this, a two-dimensional journey is proposed, first a theoretical conceptual debate and on the other hand a historical approach dealing with the emergence of the concept in recent Chilean history, with the interest of understanding a socio-territorial and historical dimension of what happened in October 2019.
\end{abstract}

Keywords: geography, historiography, interdisciplinarity, society, nature.

\title{
1. Introducción
}

El despertar de octubre de 2019 en Chile, puede considerarse un evento catártico que ha llegado para derrumbar gran parte de las certezas que como sociedad habíamos construido sobre lo que somos, cómo nos desarrollamos y vinculamos a través del pacto social. Las razones del denominado "estallido social" son múltiples y dan cuenta de una serie de desequilibrios normativos que el modelo neoliberal provoca en todas las aristas de la

Revista de Humanidades de Valparaíso, 2021, No 17, 115-143

(c) (1)@@ CC BY-NC-ND 
Espacio y territorio como categorías para la comprensión del tiempo presente...

Carla Marchant Santiago; Yerko Monje-Hernández

vida social (Mayol 2019) ${ }^{1}$. Este es un desafío no menor, ya que implica afrontar nuestras debilidades, abrazar el cambio y estar dispuestos a la transformación de nuestras prácticas. Desde la reflexión académica, este proceso supone también una profunda revisión a la manera en que las diferentes Ciencias Sociales han intentado comprender e interpretar la realidad. En tal sentido, este trabajo busca plantear algunas reflexiones que permitan avanzar en el desarrollo de ensamblajes teóricos que faciliten la integración y dialogo entre categorías conceptuales que, normalmente, se han presentado como líneas paralelas, con escasas posibilidades de interceptarse durante gran parte del siglo XIX y XX, salvo algunos momentos específicos. Nos referimos al binomio tiempo y espacio, representados como objeto de estudio de la Historia y la Geografía respectivamente.

Proponemos que, gracias a la renovada valorización de la estrecha relación temporalidad - espacialidad (Aliste y Núñez 2015), iniciada y materializada en los aportes de una creciente incorporación de estudios territoriales desde las Ciencias Sociales, es posible y deseable ampliar nuestras categorías de análisis, promoviendo un diálogo interdisciplinar que en algún momento tuvo un incipiente lugar. Desarrollaremos estas ideas a partir de una lectura de los movimientos sociales vinculados a problemáticas socioambientales del sur de Chile y cómo las demandas de estos espacios rurales se visibilizan y aúnan en el estallido social de octubre de 2019. Consideramos que un evento como este, requiere de una interpretación que de cuenta sobre cómo las espacialidades rurales, en tanto producciones socioculturales variables y marcadas por el paso del tiempo, han vivenciado y experienciado los efectos de la implementación del modelo neoliberal, que llevaron al mayor levantamiento popular de los últimos 30 años. En este sentido, cabe preguntarse ¿cómo se han plasmado las categorías de espacio y territorio en el análisis de los conflictos medioambientales recientes en Chile? ¿Han contribuido estos movimientos, surgidos desde problemáticas localizadas en los espacios rurales, a visibilizar la necesidad de revisitar las categorías socioespaciales para su comprensión? ¿Cómo se materializaron las demandas de los espacios rurales en el estallido de octubre? ¿Qué caminos se abren a partir de este momento histórico?

\footnotetext{
${ }^{1}$ La producción académica en torno al estallido social de Chile es variada y extensa. En este sentido, y para no desviar el argumento principal de este trabajo, recomendamos al lector revisar los trabajos del sociólogo Alberto Mayol (2019) y del periodista Óscar Contardo (2019), quienes describen en profundidad las diversas aristas de la crisis social, las que pueden agruparse en dos grandes temas: la deslegitimación de la clase política y de las instituciones y por otro lado, las consecuencias lógicas del repliegue excesivo del Estado en su rol de garante de derechos sociales indispensables para la vida, como la educación, salud y previsión social. La combinación de estos elementos ha provocado la generación del denominado "malestar social", el cual es abordado por los autores desde diversos puntos de interés.
}

Revista de Humanidades de Valparaíso, 2021, No 17, 115-143 
Espacio y territorio como categorías para la comprensión del tiempo presente...

Carla Marchant Santiago; Yerko Monje-Hernández

\section{El espacio. Un breve recorrido temporal sobre esta categoría geográfica por ex- celencia}

En la construcción epistemológica de la disciplina geográfica, la concepción del espacio ha sido un aspecto central de la discusión, lo que ha significado la generación de una tradición de pensamiento rica, diversa y hasta cierto punto, de marcos teóricos contradictorios. Durante la Edad Moderna, el espacio y la naturaleza eran consideradas dimensiones estáticas de la existencia humana (Ramírez y López 2015). Asimismo, el trabajo de filósofos como Immanuel Kant y de naturalistas como Alexander von Humbol$\mathrm{dt}$, fue fundamental para posicionar a la Geografía como una disciplina eminentemente física, cuya misión fue constreñida a "realizar la descripción física del mundo, ofreciendo un cuadro de lo que coexiste en el espacio, de la acción de las fuerzas naturales y de los fenómenos que estas producen" (Ortega-Valcárcel 2000,129). Este enfoque situaba al espacio como contenedor y soporte del paisaje, el cual era comprendido como producto de una interacción de los elementos físicos como el relieve, la geomorfología, el clima, el suelo y la vegetación (Vargas 2012). Estas ideas naturalistas influyeron también en el proyecto de desarrollo de la 'Antropogeografía', encarnada en el pensamiento del geógrafo y zoólogo alemán Friedrich Ratzel, quien señalaba influenciado por los postulados del determinismo, que el ser humano y las sociedades son un objeto del medio natural y que su evolución debe explicarse en función de las circunstancias geográficas exteriores (Gómez 2006). Es así como la institucionalización de la disciplina, en el último cuarto del siglo XIX se realizaría con una noción de espacio restringido a la condición de lo material (Ortega-Valcárcel 2000).

Una voz disidente de esta visión fue representada por el geógrafo anarquista francés Élisée Reclus, quien planteó la idea de un espacio visto no solo como componente físico, sino un elemento de acción combinada con las personas que construyen su espacio (Vargas 2012; Quesada 2015). A él se sumarían otros geógrafos franceses como Paul Vidal de La Blache, quien a fines del siglo XIX propuso el concepto de región como unidad espacial, donde el espacio general está formado por 'unidades espaciales' funcionales, que tienen características homogéneas, propias y únicas. Esta reflexión será abordada por el historiador Lucien Febvre (1970a [1922]), quien la denominó como posibilismo y permitió el surgimiento de un renovado diálogo entre la Geografía y la Historia, a través del desarrollo de la "Escuela de los Annales", corriente historiográfica que acercó además su quehacer a otras Ciencias Sociales, como la Sociología, integrando métodos y enfoques e interesándose por los procesos y las estructuras sociales a partir de preguntas por resolver, interpretando dichos procesos, incluyendo sus propios conceptos y subjetividad.

Sin embargo, el enfoque y tratamiento cientificista de la categoría espacial predominaría, perdurando hasta la primera mitad del siglo XX, refrendado principalmente por las ideas del Círculo de Viena, movimiento creado por Moritz Schlick en 1929 que abogaba por la concepción científica del mundo, la relevancia de la evidencia empírica y la construcción de teorías que permitieran contribuir al conocimiento científico universal. Lo

Revista de Humanidades de Valparaíso, 2021, No 17, 115-143

(c) $(1)(9)$ CC BY-NC-ND 
Espacio y territorio como categorías para la comprensión del tiempo presente...

Carla Marchant Santiago; Yerko Monje-Hernández

anterior reforzó y contribuyó a la consolidación del paradigma positivista, caracterizado por la lógica matemática y exactitud que aspiraba a una concepción de la Geografía como una "ciencia de la organización del espacio" (Gómez 1979). Esto se debe principalmente a la influencia de los modelos espaciales sugeridos a principios del siglo XIX por el economista alemán Johann Von Thünen, quien desarrolló en 1826 una teoría para entender y organizar el crecimiento de las ciudades, la relación campo-ciudad y la especialización de la producción a su alrededor. Posteriormente, diversos geógrafos y escuelas acogieron este enfoque y los principios de la economía espacial desarrollada por Christaller (1933) y Losch (1940), quienes presentan la Geografía como la matemática del espacio, concebido este como homogéneo e isotrópico.

Ya en la segunda mitad del siglo XX, y gracias al debate producido por la obra Excepcionalismo en Geografía de Fred Schaefer - que según Capel planteó con claridad la mayor parte de los problemas epistemológicos de la disciplina (1971, 10 y ss.) - , fue posible que se produjera un cambio paradigmático, con el trabajo de las más destacadas figuras de la Nueva Geografía.. Principalmente, Schaefer cuestionó el carácter descriptivo y enfocado a las clasificaciones de la disciplina e hizo un llamado a la Geografía a adaptarse a métodos verdaderamente científicos y originales, que permitieran avanzar hacia la generación de leyes generales. Lo anterior consolidaría la relevancia del paradigma del análisis espacial, el que fue fructíferamente adoptado en las escuelas anglosajonas de Geografía. Según Peter Haggett (1994), uno de los más destacados representantes de esta corriente, los geógrafos se abocaron a identificar estructuras espaciales tales como los flujos, las redes, los nodos, las jerarquías y a explicar fenómenos como la difusión espacial.

Ya en la década de 1960, el predominio de esta visión cuantitativa del espacio y del rol de la Geografía, será objeto de una fuerte crítica por parte de algunos geógrafos que argumentarán la obsolescencia de estos planteamientos, especialmente por su incapacidad de capturar la dimensión humana, fundamental para comprender los fenómenos de la superficie terrestre (Ramírez y López 2015). Además se criticaba la incapacidad de este enfoque de generar cambios, tanto en la sociedad, como a nivel científico. Estos cuestionamientos provenían principalmente de nuevas corrientes epistemológicas, como las geografías radicales, principalmente marxistas y humanistas, quienes abogaban por la necesidad de un mayor compromiso social de la disciplina en su rol de denunciar las situaciones de desigualdad que aquejaban a la humanidad de la postguerra. Asimismo, según Ramírez y López (2015), en la corriente marxista, la visión social del espacio como parte de la impronta que la producción económica deja en el mismo, es parte fundamental de su desarrollo y comprensión. Igualmente, se incorpora la concepción del espacio social producido por las relaciones sociales, y también las relaciones entre la sociedad y la naturaleza. Esta última incluye tanto la naturaleza prístina, como la naturaleza transformada por el trabajo humano o segunda naturaleza, según lo planteara el geógrafo Neil Smith (1984). Por otro lado, Hiernaux y Lindón (2006), señalan que la crítica apuntó al hecho de que los procesos sociales generan una impronta en el espacio y, por ende, la concepción 
Espacio y territorio como categorías para la comprensión del tiempo presente...

Carla Marchant Santiago; Yerko Monje-Hernández

de espacio como reflejo de las relaciones sociales, es sin duda su corolario de la totalidad del mismo. Esta relevancia de la vinculación a la dimensión temporal es también reflejada en el planteamiento de Doreen Massey, geógrafa británica, quien señala que, bajo la lógica positivista, los análisis estaban fuera de la historia y de la organización social de las cosas y por sobretodo, que no existía una diferenciación geográfica en los planteamientos, debido a que no hay solamente procesos espaciales, sino que son "procesos sociales que operan sobre el espacio" $(1985,11)$.

Asimismo, influyen en esta crítica, el acercamiento de geógrafos urbanos al trabajo de filósofos como Henri Lefebvre (1969), quien debate en su obra fundamental El derecho a la ciudad, sobre el espacio urbano, las ciudades y la excesiva importancia dada a estas por el capitalismo en el siglo XX y por el Estado en la reconstrucción de postguerra. Esta crítica permitirá también transitar a la Geografía hacia la comprensión del espacio desde una perspectiva social y también de producción (Lefebvre 1974), permitiendo incorporar algunas ideas clave que promovieron un cambio de enfoque, como la consideración del espacio de manera inseparable de la práctica social. Esta idea fue acogida y profundizada por David Harvey, geógrafo británico considerado uno de los principales exponentes de la corriente marxista en la disciplina y que ha desarrollado una prolífera producción académica orientada al debate de las categorías geográficas, especialmente representadas en su concepción de construcción social del espacio y el tiempo. En este sentido, Harvey se refiere al espacio como una categoría dinámica, variable, señalando además que:

Diferentes sociedades construyen concepciones muy específicas del espacio y del tiempo. Más aún, la manera verdadera de construir el espacio y el tiempo es muy importante para mirar cómo nosotros, en nuestras circunstancias contemporáneas, estamos construyendo y sosteniendo ciertas nociones de espacio y de tiempo en detrimento de otras... las medidas de espacio y de tiempo, que hoy tratamos como condiciones naturales de la existencia, fueron de hecho productos históricos de un conjunto muy particular de procesos históricos específicos alcanzados dentro de un tipo de sociedad determinada. $(1994,2)$

Al respecto, Castree (2011) señala que para Harvey, la naturaleza del espacio está en la práctica humana, rechazando la existencia de un espacio polarizado o en binomio, proporcionándole así una dimensión de "momento activo" en los problemas humanos. Por otro lado, el tratamiento del espacio desde la visión humanista, encontró sus fundamentos en la Fenomenología y el Existencialismo, aportando por esta vía, la dimensión subjetiva al estudio de la problemática espacial, considerando para su definición sentimientos y emociones. En esta línea, destaca la obra del geógrafo chino-estadounidense Yi $\mathrm{Fu}$ Tuan (1979), quien señala la relevancia de la experiencia en el estudio del espacio y de los sentimientos espaciales, los cuales se construyen a partir de las sensaciones, de la percepción y las concepciones. Con ello, se reafirma el carácter singular del espacio y sus

Revista de Humanidades de Valparaíso, 2021, No 17, 115-143 
Espacio y territorio como categorías para la comprensión del tiempo presente...

Carla Marchant Santiago; Yerko Monje-Hernández

procesos. Esta interpretación contrastaría con la idea de un espacio abstracto y matemático y alejado de la experiencia, por lo cual, los geógrafos humanistas incursionaron en el desarrollo del concepto de lugar, impulsando un camino propio que permitiera reconocer esta singularidad.

Finalmente, cabe destacar la visión posmoderna del espacio, impulsada en la década de los ochenta, como un cuestionamiento a la promesa de transformación y liberación que la modernidad capitalista ofreció y no cumplió. Además en este periodo se realza la idea que el espacio se había subyugado al tiempo (Ramírez y López 2015). Estas reflexiones fueron iniciadas por la Escuela de Frankfurt y se extenderían en la segunda mitad del siglo XX, existiendo múltiples posturas y visiones sobre cómo definir y abordar las categorías de tiempo y espacio, desde la configuración espacial del poder y sus discursos, representada por Foucault (2010), o el giro culturalista del espacio representado por Edward Soja $(1980 ; 1989)$ en su trialéctica del espacio (espacialidad - temporalidad - socialidad) o la visión del espacio como flujos y la sociedad de la información representada por Castells (1997).

Para concluir este breve recorrido sobre la evolución de la categoría de "espacio", cabe destacar el aporte desde la Geografía latinoamericana crítica realizado por el geógrafo brasileño Milton Santos, quien es un referente al momento de instalar una corriente epistemológica desde el sur del mundo. En su obra La naturaleza del espacio (1996), Santos señala que tiempo y espacio son dimensiones separadas, aunque de formas específicas, la técnica, (es decir el método para analizarlas) las une. Asimismo, asume como homólogos los conceptos de espacio y territorio y define el espacio como:

Un conjunto de fijos y flujos. Los elementos fijos, fijados en cada lugar, permiten acciones que modifican el propio lugar, flujos nuevos o renovados que recrean las condiciones ambientales y las condiciones sociales, y redefinen cada lugar. Los flujos son un resultado directo o indirecto de las acciones y atraviesan o se instalan en los fijos, modificando su significación y su valor, al mismo tiempo que ellos también se modifican. $(2000,53)$

Esta breve exposición sobre los enfoques que se han desarrollado desde la Geografía, principalmente en el contexto de la modernidad para comprender el espacio, nos invita a retomar esta categoría dinámica, que se ha construido y resignificado con el paso del tiempo y especialmente desde el inicio de la posmodernidad, cuando se diversifican las interpretaciones. En este sentido, en palabras de Ortega-Valcárcel "el espacio geográfico representa una elaboración o construcción específica de esa dimensión social, es decir el objeto de la Geografía" (2020, 339). De igual forma lo plantea Rogério Haesbaert (2010), señalando que el espacio es la categoría esencial en la "constelación geográfica de conceptos" (espacio - región - territorio), y que por tanto la Geografía es la disciplina enfocada en la dimensión espacial de la sociedad. 
Espacio y territorio como categorías para la comprensión del tiempo presente...

Carla Marchant Santiago; Yerko Monje-Hernández

Ahora bien, el llamado giro territorial de las Ciencias Sociales (Capel 2016), nos obliga a reflexionar brevemente sobre el desarrollo y evolución de las categorías utilizadas. ¿Cómo transitamos entonces, de la aplicación de la categoría de "espacio" a la de "territorio"? De acuerdo con Ramírez y López (2015), la categoría de territorio no tiene una tradición histórica en la filosofía y su desarrollo se ha asociado principalmente al campo de los trabajos de la geografía política o de la política propiamente tal, al referir principalmente a la creación de estados nacionales y la definición de fronteras. Esta acepción de delimitación y apropiación de la superficie terrestre transforma al territorio en una categoría mucho más concreta y particular que la de espacio; al mismo tiempo, es más especializada, ya que vincula a la sociedad con la tierra y la naturaleza, pero no desde su apariencia o representación, sino desde su apropiación, uso o transformación y alude tanto a una perspectiva política y cultural. Por ello ha sido más utilizada en las ciencias sociales de corte más crítico, para superar los dilemas de las concepciones tradicionales del espacio que hemos destallado anteriormente.

Sin embargo, sin entrar necesariamente en un amplio debate sobre las diferentes acepciones de uso de la categoría 'territorio', es importante señalar que George (2004) en su diccionario de Geografía Humana, identifica ocho formas de utilizarlo, a saber: (i) desde el análisis espacial como un espacio excepcional, no comparable; (ii) como sinónimo de espacio y por tanto como término intercambiable; (iii) como sinónimo de lugar y en esta acepción como oposición a lo global; (iv) como una construcción intelectual abstracta, el referido a la dimensión real del espacio socializado; (v) como un espacio delimitado y controlado; (vi) como concepto relacionado con la conducta animal y en este sentido vinculado al dominio del espacio; (vii) como espacio apropiado, relacionado a la identidad y (viii) como una periodización histórica.

En el contexto de la reflexión que este trabajo busca realizar, consideramos adecuado pensar en espacio y territorio como sinónimos, si lo entendemos en los términos de la propuesta de Raffestin (1986) quien define el territorio como un espacio transformado por la acción humana, reafirmando su importancia como objeto de estudio de la geografía social. A nuestro entender, esta definición permite, además, concebir al territorio como "un eje a partir del cual podrían plantearse adecuadamente ciertos problemas y estimular la colaboración interdisciplinaria" (Capel 2016, 1), en este caso un dialogo entre Historia y Geografía. Es así como cabe preguntase ¿cómo se están reencontrando las categorías de espacio y tiempo en la producción académica en este contexto de revalorización de la dimensión territorial? ¿Cómo se operativiza esta nueva visión? Y más aún ¿cómo está ocurriendo este proceso, en torno al abordaje de problemáticas del espacio rural chileno? 
Espacio y territorio como categorías para la comprensión del tiempo presente...

Carla Marchant Santiago; Yerko Monje-Hernández

\section{Espacio - tiempo: un reencuentro necesario para comprender la complejidad de lo social}

Si bien parece obvio indicar la interacción entre espacio y tiempo para la comprensión de los fenómenos sociales en un plano actual y de largo plazo, de cierta manera el auge de trabajos interdisciplinares que ponen en el centro las dinámicas espaciales y sociales, pueden crear la ilusión de cierta novedad en las unidades de análisis. Sin embargo, la interacción de estas dos categorías, recoge un amplio debate que fácilmente puede remontarse varias décadas atrás como se aprontó en el apartado anterior. Desde una impronta de carácter historiográfica, resultan claves las propuestas sobre tiempo y espacio que han presentado dos corrientes fundamentales como el marxismo (británico, sobre todo) y la Escuela de los Annales, cuyas reflexiones versan con fuerza sobre la interacción precisamente entre la Historia y Geografía, como parte de un mismo problema en torno a la comprensión de los fenómenos sociales. Por tanto, instalado en estas reflexiones, no resulta extraña la invitación que haría Lucién Febvre en Combates por la historia (1970b [1953]) para que los historiadores asuman las multidimensionalidades del quehacer investigativo.

Considerando lo anterior, la idea de tiempo y más precisamente del tiempo histórico, ha resultado también un problema en sí mismo para la comprensión de los fenómenos sociales. Marc Bloch, en su obra Apología para la Historia o el oficio del historiador (1996 [1949]), ya planteaba que no basta con comprender la Historia como el estudio de la humanidad, sino que debía complementarse con la salvedad que es el estudio de los fenómenos humanos en el tiempo. Aunque hoy nos parezca un detalle menor, esta afirmación recogió una noción del tiempo de carácter complejizada, dinámica y móvil, y profundamente contestataria al positivismo instalado desde las universidades que cultivaban la disciplina de manera mayoritaria.

Es menester indicar que antes de la profesionalización de la Historia en el Siglo XIX en occidente, existieron múltiples y variados debates en torno a la idea del tiempo histórico y sus ciclos (Aurell, Balmaceda, Burke y Soza 2013; Iggers 2012). Por ejemplo, en la época clásica con las reflexiones históricas de los primeros cultivadores del saber/pasado como Heródoto de Halicarnaso, Polibio y Luciano de Samósata por nombrar algunos destacados, existía una concepción del tiempo como un elemento cíclico, por el cual el estudio del pasado tomaba un rol pedagogizante en la medida que se instala a la Historia como una maestra de la vida, en términos de Cicerón. Sin embargo, a partir del siglo $\mathrm{V}$ esta idea del tiempo histórico cíclico cambia con la hegemonía cultural del cristianismo, instalándose la idea de un tiempo lineal, con un inicio y final dado en los tiempos de Dios. Siglos más tarde, con el cultivo de una perspectiva racionalista moderna, Giambattista Vico (2006 [1725]) comprendería el tiempo histórico como una conjunción de ambas tradiciones, otorgando un sentido de proyección eterna, pero con ciclos, dotando de un sentido de espiral al tiempo histórico.

Revista de Humanidades de Valparaíso, 2021, No 17, 115-143

(c) $(1)(9)$ CC BY-NC-ND 
Espacio y territorio como categorías para la comprensión del tiempo presente...

Carla Marchant Santiago; Yerko Monje-Hernández

Más allá de las diferencias y semejanzas entre estas concepciones del tiempo, resulta interesante que tanto en las antiguas visiones de una primera etapa de sistematización del pensamiento histórico, y la visión profesionalizada de la historiografía, el tiempo estaba asociado a lo humano, por tanto, también su acción y comprensión (Bloch, 1996 [1949]). Sin embargo, en una segunda generación de la Escuela de los Annales, con Fernand Braudel y la insigne obra "El Mediterráneo y el mundo mediterráneo en la época de Felipe II" (2019 [1949]), la idea del tiempo histórico es transformada y reconocida en una triple dimensionalidad, que instalaba la asociación de tiempo y la acción humana como una parte más de la ecuación, presentando un tiempo de larga duración que incluye los tiempos de la espacialidad y la Geografía, uno de mediano plazo asociado a las coyunturas sociohistóricas y finalmente la corta duración o el acontecimiento, que instalaría en ese plano a la historiografía positivista de lo factual, memorística y centrada en personajes.

Precisamente este trabajo instalaría un afán revolucionario en las investigaciones historiográficas e inclusive geográficas con la referencia a grandes clásicos de aquella disciplina como Paul Vidal de La Blache. Sin embargo, a pesar de su importancia e influencia en el pensamiento histórico y del tiempo como categoría de análisis, paulatinamente la influencia del marxismo británico fue instalando un acento puesto en los sujetos y colectivos sociales, que, si bien no desconocía elementos como la materialidad de la historia, daría una impronta social entendida como experiencia vivida, a los estudios historiográficos que hasta hoy es posible pesquisar.

Recientemente la idea de tiempo histórico ha vuelto a reconocer la pluralidad de sus dimensiones a partir de dos elementos. El primero de ellos orientado a una impronta interdisciplinar que rescata de cierta manera la tarea e invitación realizada por los Annales para la comprensión de los fenómenos sociales y económicos. Por otra parte, la puesta en valor de la materialidad y el espacio de lecturas teóricas que recogen una economía política profundamente espacializada, tal como hemos destacado en un primer apartado de esta reflexión, a propósito de la categoría de espacio y territorio.

Precisamente en torno al espacio, tal como plantean Aliste y Núñez (2015), a pesar de los casos destacados, durante gran parte del siglo XIX y XX primó una concepción del tiempo como dinámico y el espacio como inerte, lo cual consideramos contribuyó a desatender esta categoría en los análisis realizados desde las Ciencias Sociales, disociando el espacio del tiempo y sobrevalorando únicamente esta última categoría. En el caso chileno, la misma Geografía abrazó sin mayores cuestionamientos el paradigma positivista decimonónico, acercando su quehacer hacia las ciencias naturales, tendencia que calaría hondo en el quehacer de los geógrafos que colaboraron a la institucionalización de la disciplina en el país (Quiroz y Narváez 2014). Esto se acentuaría aún más en la década de los setenta, cuando debido a la dictadura cívico militar, la Geografía chilena, se alejaría aun más de las Ciencias Sociales y de su rol de indagación de problemáticas sociales y humanas. Sin embargo, a partir de la década de los noventa, esta tendencia se ha revertido, a partir del trabajo realizado en el ámbito de la geografía urbana por connotados

Revista de Humanidades de Valparaíso, 2021, No 17, 115-143

(c) $(9)(9)$ CC BY-NC-ND 
Espacio y territorio como categorías para la comprensión del tiempo presente...

Carla Marchant Santiago; Yerko Monje-Hernández

geógrafos ${ }^{2}$, y en las últimas décadas, reforzada por la reflexión conjunta entre geógrafos e historiadores que han desarrollado de acuerdo con Aliste y Núñez la "idea de una espacialidad cuyo sentido surge desde una producción sociocultural que varía de acuerdo con las diversas épocas" $(2015,288)$.

Desde la historiografía, por ejemplo, a partir de la década del noventa se desarrollaron algunas agendas investigativas que problematizaron la espacialidad en relación con la experiencia de los colectivos. Perspectivas como la historia urbana con Armando De Ramón (1985; 2002) plasmarían la necesidad de comprender las dinámicas urbanas como fenómenos históricos, lo que más tarde sería entendido claramente desde los estudios urbanos con la rehabilitación de la tesis de Henri Lefebvre (1974). En esta misma línea, el trabajo de Sergio González (2015) desde la historia regional, también problematizaría desde la espacialidad su estudio sobre la triple frontera andina.

En la actualidad la relación entre tiempo y espacio ha recibido un nuevo impulso, desde la interdisciplinariedad del trabajo con la Historia, Geografía, Antropología y Economía, inclusive planteándose un nuevo enfoque o espacios de estudios asociados a un giro territorial. Ejemplos de aquello, se observan en los trabajos que abordan problemáticas territoriales medioambientales (Camus et al. 2016; Camus et al. 2017; Núñez, Aliste y Bello 2014; Aliste, Folchi y Núñez 2018; entre otros) cuyo centro recoge una doble dimensión, en el sentido de investigar una problemática específica, pero integrando las reflexiones conceptuales y teóricas. Por otra parte, desde la Historiografía también se ha entrado en este análisis con recientes publicaciones como las de Harambour (2019) y Almonacid (2020) que ponen en evidencia desde un afán histórico, la preocupación por los espacios del capital en distintos periodos del siglo XIX y XX, hasta la actualidad.

Esta producción académica nos permite abrir nuevas perspectivas en torno al abordaje que, desde este renovado vínculo entre la Geografía y la Historia, primeramente, pero también con otras Ciencias Sociales es posible desarrollar. Para ello la superación de los análisis disciplinares es fundamental, relevando la importancia de volver con más énfasis en el análisis del espacio a partir de sus procesos de significación histórica, realizados por las sociedades y abogando también por otros enfoques metodológicos.

\section{Los debates sobre el espacio, territorio y sociedad en la historia reciente chilena}

Tal como hemos indicado en los apartados anteriores, el debate conceptual en torno al espacio y tiempo tiene una profundidad y tradición tan densa y extensa como su propio desarrollo disciplinar. Este devenir categorial evidentemente expresa una interrogación

\footnotetext{
${ }^{2}$ Nos referimos a la línea de investigación sobre estudios urbanos impulsada por el geógrafo Patricio Larraín en el Instituto de Geografía de la Pontificia Universidad Católica de Chile en la década de los ochenta y noventa y al trabajo desarrollado posteriormente por Rodrigo Hidalgo, con su vasta producción sobre el estudio de la ciudad, desde la perspectiva geográfica y social.
}

Revista de Humanidades de Valparaíso, 2021, No 17, 115-143

(c) $(1)(9)$ CC BY-NC-ND 
Espacio y territorio como categorías para la comprensión del tiempo presente...

Carla Marchant Santiago; Yerko Monje-Hernández

abierta y amplia, no sólo desde una perspectiva filosófica, epistemológica e inclusive metodológica, sino que hace necesario recoger la propia historicidad de los espacios y territorios, para otorgar una impronta situada y profundamente histórica al debate. Como indica Aliste (2014) hoy más que nunca existe una necesidad por abrir campos analíticos, para reflexionar el modo en que construimos nuestras observaciones y la interpretación de la realidad observada. Lo anterior, especialmente en un momento histórico de cuestionamiento a las estructuras sociales, del cual las universidades y la producción de conocimiento no quedan aisladas.

En este sentido, se hace necesario comprender que el ejercicio de reflexionar a un nivel de carácter histórico/territorial no solo implica una revisión de fuentes y documentos como lectura mecánica de lo acontecido como real pasado. Como se hace evidente en corrientes asociadas a un trabajo de Historia del Tiempo Presente, Reciente o Contemporánea, el quehacer histórico e historiográfico se vislumbra como un productor y actualizador de la propia caja de herramientas con la que se interroga la realidad social, comprendiendo esto a un nivel metodológico y teórico. Por tanto, la reflexión categorial presentada, reconoce en el propio rescate de la historicidad de los espacios y territorios regionales, una actualización de las categorías otorgando la posibilidad de revitalizar y situar las teorías desde la propia reflexión histórica (Franco y Levín 2007; Sábato 2007; Illanes 2003; Aróstegui 2004; Almonacid 2020).

En concordancia a lo indicado, la dinámica histórica de los espacios y territorios arroja una profundidad y sustrato que ciertamente extiende una dinámica de larga duración (Braudel 2019 [1949]) cuyo análisis requeriría tratados y trabajos que superan este esfuerzo reflexivo. La relación entre espacio/territorio y la historia, supone un debate que instala en su centro elementos tan sustanciales como la propia diada sociedad y naturaleza, tan ampliamente desarrollada desde el marxismo, a un nivel de reflexión disciplinar geográfica e historiográfica. Ejemplo de lo planteado, lo podemos encontrar en el trabajo de Thomas Kublock (2012) quien presenta una reflexión contemporánea sobre la historia ambiental e historia social, cuya tesis da cuenta que a pesar del auge que han tenido los estudios sobre las dinámicas territoriales en la actualidad, es un debate que tiene una profundidad histórica tan amplia como los propios orígenes del capitalismo y más.

Ahora bien, considerando los horizontes de amplitud y profundidad que requiere el reconocimiento de la categoría de espacio y territorio, evidentemente en una dinámica reciente hay elementos que otorgan características propias al ciclo actual, cuyo auge está profundamente relacionado al llamado estallido social de octubre de 2019, periodo en el cual se evidenciaron tensiones y contradicciones que hace décadas acarreó el modelo de desarrollo neoliberal, y venían denunciando distintas comunidades en espacios y territorios regionales.

Tal como indican Postigo, Blanco y Chacón (2015) la atención de las Ciencias Sociales a los conflictos socioambientales, movimientos sociales y degradación ambiental 
Espacio y territorio como categorías para la comprensión del tiempo presente...

Carla Marchant Santiago; Yerko Monje-Hernández

comienza a tener un desarrollo a partir de la década de 1970. Sin embargo, el auge de estas investigaciones está en pleno apogeo, instalando muchos de estos conflictos como novedad investigativa, a pesar de la extensión de su desarrollo cronológico. Por ejemplo, sería extraño presentar como un elemento reciente la defensa de los territorios ancestrales por parte de comunidades indígenas, cuando la espesura cronológica de esta contradicción puede arrojarse varios siglos atrás con facilidad. Por ello, a continuación de un criterio asociado a una historia reciente de estos conflictos ambientales, daremos un vistazo a momentos que nos parecen constitutivos y claves de las dinámicas sociales y geográficas recientes, cuyo impacto justifica la reflexión categorial que este trabajo busca instalar.

Con el propósito de comprender este debate en la historia reciente chilena, en los siguientes apartados se expondrá en torno a tres momentos fundamentales para identificar las dinámicas entre tiempo y espacio. El primero orientado al conflicto de la represa Ralco en el Alto Biobío como uno de los primeros desencuentros en transición democrática, que marcó la necesidad por constituir una institucionalidad ambiental en la regulación chilena. El segundo en torno al conflicto ambiental del Santuario del Río Cruces en la actual Región de Los Ríos, como un momento de cuestionamiento a esa regulación, por un lado, y de articulación ciudadana por otro. Y finalmente, se presenta el movimiento de "Patagonia Sin Represas" como un momento constitutivo de la instalación de la demanda socioambiental en la agenda nacional, en uno de los ciclos de movilización más activos en la historia reciente.

\subsection{De Ralco (Alto Biobío) al Movimiento de Defensa por los Cisnes (Valdivia). Con- flictos Socioambientales que sobrepasan la escala local}

Tempranamente en la década del noventa, en conjunto con los procesos de democratización nacional tras la reciente finalización de la dictadura civil-militar de Augusto Pinochet, comenzaron a aflorar los primeros conflictos socioambientales en un marco de historia reciente. Rojas, Sabatini y Sepúlveda (2003) planteaban una irrupción de estos conflictos, en la medida que avanzaban los procesos de democratización en la sociedad chilena, y en paralelo a la profundización del modelo neoliberal que influyó en su agudización. No resulta extraño entonces, que en 1994 se creara la Comisión Nacional de Medio Ambiente (CONAMA) en paralelo al desarrollo de los Estudios de Impacto Ambiental (EIA) para proyectos de gran envergadura.

En una primera etapa de este breve recorrido histórico reciente, las tensiones de la matriz energética nacional se instalaron como un elemento en el debate público de este naciente ciclo de movilización. A decir de Blanco-Wells (2019), estos conflictos instalados 
Espacio y territorio como categorías para la comprensión del tiempo presente...

Carla Marchant Santiago; Yerko Monje-Hernández

en la denominada vida social de la energía ${ }^{3}$ dan cuenta de una lógica contemporánea de las contradicciones entre sociedad y naturaleza, evidenciando con fuerza las denominadas tensiones del modelo económico que se hacían evidentes ante la posibilidad de retomar ciertas dinámicas de protesta en la década del noventa, que evidenciarían las luchas por el espacio y territorio como eje central, especialmente en aquellos ligados a proyectos energéticos, como fue el caso de Ralco en Alto Biobío.

Reconociendo que la hidroelectricidad ha sido un componente principal de la matriz energética de Chile desde finales del siglo XIX, Höhl (2018) indica que el conflicto de Ralco se perfiló como uno de los principales capítulos sobre esta dimensión en la historia chilena. Siguiendo lo planteado por Bauer en Höhl (2018) la construcción de la represa Ralco causó controversias a nivel internacional acerca de derechos ambientales e indígenas en Chile, aprontando sin duda, una inflexión en la espacialidad y territorialidad del conflicto social.

Ralco fue un proyecto hidroeléctrico (central hidroeléctrica) impulsado por ENDESA - otrora estatal Empresa Nacional de Electricidad S.A. privatizada en dictadura - en un marco de una política de desarrollo energética profundamente centralista, urbanizada y entregada al mercado energético nacional y mundializado en términos de capital. El proyecto está ubicado en la comuna de Alto Biobío, 120 kilómetros al sureste de Los Ángeles, en los límites de la Región del Biobío y la Araucanía, en pleno territorio pewenche. Esta iniciativa vislumbró rápidamente las tensiones y disputas del espacio y territorio entre las comunidades, Estado y empresas. Con una inversión total que superó los 490 millones de dólares, Ralco puso rápidamente en una encrucijada a la reciente institucionalidad ambiental, en paralelo a la promulgación de una criticada Ley Indígena y formación de la Corporación Nacional de Desarrollo Indígena - CONADI. En 1994 ENDESA presenta de manera voluntaria un estudio de impacto ambiental el proyecto, que se extendió por varios años, sin embargo, la empresa decide de manera unilateral comenzar la construcción del complejo energético en 1995, dando los primeros anticipos del conflicto que se gestaría, ante la crítica abierta y generalizada de los pewenche.

El conflicto tendría su base en la arbitrariedad de varias decisiones, partiendo por el fallo de CONAMA que en 1997 aprobó el proyecto, dando cuenta de una decisión política del Estado ante el desarrollo de estas iniciativas (Kaltmeier en Höhl, 2018). A decir de Moraga la crítica se situaba en que:

ENDESA (primero como una empresa privada chilena y luego como parte de la transnacional española del mismo nombre) ha avanzado en sus planes de construir Ralco sin importar los costos sociales, culturales y económicos que esto signifique

\footnotetext{
${ }^{3}$ Según el autor, la propuesta teórica y metodológica que implica esta denominación pasa por el estudio de los procesos territoriales, las prácticas organizativas, los usos, los significados y las disputas alrededor de la producción y el consumo de energía. (Blanco-Wells 2019, 161)
} 
Espacio y territorio como categorías para la comprensión del tiempo presente...

Carla Marchant Santiago; Yerko Monje-Hernández

para el pueblo mapuche pehuenche y para el ecosistema del río más importante de Chile. En este camino, también ha desestimado los costos políticos del conflicto, que han llevado a convertir Ralco en el punto inicial de un nuevo quiebre entre el Estado chileno y los pueblos indígenas. $(2001,6)$

La matriz de este conflicto estaría dada en lo que sería entendido como usurpación de territorios ancestrales, la carencia de respeto desde el propio Estado a los medios y formas de vida de comunidades indígenas mapuche-pewenche, lo que implicaba la negación de sus derechos colectivos como pueblos, pasando por encima de la Ley Indígena promulgada en 1993 y Convenio 169 de la Organización Internacional del Trabajo. A pesar de los empeños desde CONADI por frenar el proyecto amparado en la reglamentación, el afán estatal por dar el vamos al proyecto fue mayor.

Tras las permutas de tierras a comienzos de 1999, ENDESA continuó con las obras. Sin embargo, como rescata Höhl (2018) la activación de repertorios de movilización social desde las propias comunidades daría otro cariz a este conflicto, especialmente a partir de un grupo de seis mujeres que comenzó a presentar recursos de protección en diferentes tribunales nacionales, y cuando la justicia chilena falló a favor del proyecto, recurrieron a la Corte Interamericana de Derechos Humanos - CIDH.

En el intertanto, en 2003 la Comisión Nacional de Energía presentó una postura favorable a la central hidroeléctrica, buscando dar señales para que se extendieran estas inversiones en el territorio nacional. Finalmente, la iniciativa entró en funcionamiento en 2004, reubicando a 675 personas, de las cuales 500 eras pertenecientes a comunidades pewenche, en medio de la inundación de más de 3 mil 500 hectáreas. En este sentido, Ralco sentó una precedente que, a pesar de este proceso de democratización nacional, la hegemonía económica y política no recogió otras visiones sobre desarrollo o formas de vida, disputando y apropiándose del espacio y territorio en términos economicistas (Aylwin en Rojas, Sabatini y Sepúlveda 2003).

De esta manera, el proyecto Ralco y su posterior ejecución, fue una apertura inicial y temprana a los conflictos socioambientales que caracterizarían con especial tenor, la fase neoliberal del capitalismo nacional. En este sentido, Ralco dio cuenta de las contradicciones en el entendimiento de la espacialidad de la vida y los territorios de las comunidades, mostrando la primacía de un criterio económico que ha caracterizado la mirada sobre los territorios rurales, fuera de los grandes centros urbanos en Chile. A pesar de la normativa que al parecer buscaba potenciarse de manera robusta, la impronta del Estado y su regulación neoliberal no tembló al contrariarse y desconocer sus propias iniciativas, demostrando ante todo un proyectar sin hacer. ¿No era esto mismo parte del problema denunciado en el octubre chileno de 2019?

Un segundo momento interesante para comprender el espacio y territorio como categoría para la comprensión del tiempo presente, se vislumbra en el conflicto socioambien- 
Espacio y territorio como categorías para la comprensión del tiempo presente...

Carla Marchant Santiago; Yerko Monje-Hernández

tal tras la instalación de la Celulosa Arauco y Constitución - CELCO - en la provincia de Valdivia de la otrora Región de Los Lagos, Comuna de Mariquina, actual Región de Los Ríos. Este evento nuevamente tensiona la política y regulación estatal desde una perspectiva de conflicto socioambiental, en un marco cada vez más evidente de desarrollo extractivista, que no se vio modificado tras la transición a la democracia, sino profundizado.

Al igual como aconteció en Ralco (Alto Biobío), el conflicto en la actual región de Los Ríos tuvo una impronta de tensión entre el espacio percibido como un reservorio de recursos desde una perspectiva economicista, por un lado, y desarrollo de las formas históricas del habitar por otro. El conflicto por la instalación de la planta de celulosa de CELCO y más tarde el Movimiento de Acción por los Cisnes, dejó en evidencia las consecuencias sociales y ambientales de la instalación de la industria forestal de corte extractivo y exótico, que marcaría ciertamente el panorama de la zona sur de Chile, especialmente a partir de la década del noventa (Camus 2006; Monje-Hernández 2020; Palma 2013; Martínez 2015). Sin dudas, otra arista que también fue interrogada a partir del octubre chileno.

Cabe mencionar que el establecimiento del DL 701 sobre fomento forestal (1974), fue una de las primeras trasformaciones estructurales de la dictadura, debido a que recogió en gran parte los requerimientos de los grandes propietarios y las directrices establecidas por la ciencia forestal y saber socio-técnico acumulado, especialmente en el fomento forestal a través de las bonificaciones y establecimiento de suelos para esta actividad. Como señala Camus (2006) a partir de 1975, comenzaron a operar "créditos de fomento" que eran entregados por el Banco Central a través de bancos comerciales y el Estado para estimular la forestación privada, respondiendo con ello a las propuestas de la Corporación de la Madera - CORMA. En conjunto con el sistema de explotación y bonificación anteriormente referido, el "libre mercado" tuvo su expresión en la concentración de la propiedad de la tierra y privatización de industrias creadas bajo el Estado desarrollista.

Con la instalación de CELCO en la comuna de Mariquina entrada la década del 2000, el conflicto forestal se hizo más evidente. En la medida que se efectuaron las primeras plantaciones forestales en los terrenos comprados paulatinamente por empresas pioneras en la comuna como Forestal Mininco S.A (CMPC) y Tornagaleones (actual MASISA y Hancock Chilean Plantations HCP S.A.) también se comenzó a reconfigurar radicalmente el paisaje (AIFBN 2011). De esta manera, el panorama forestal se comenzó a instalar en la Región de Los Ríos y gran parte del sur de Chile, como una impronta de desarrollo impuesta y monolítica, que marcaba de cierta manera las proyecciones y posibilidades de vida en estos territorios.

En esta dirección, cuando CELCO presentó en 1995 un EIA para instalarse con una planta de celulosa en la comuna de Mariquina, esta noticia no tomó a nadie por sorpresa, ya que hace varios años se había instalado el rumor como un justificativo para la inversión en plantaciones, que era vendida de cierta manera como una segura apuesta a futuro. Desde el momento de presentación del proyecto de producción de celulosa blanqueada,

Revista de Humanidades de Valparaíso, 2021, No 17, 115-143

(c) $(1)(9)$ CC BY-NC-ND 
Espacio y territorio como categorías para la comprensión del tiempo presente...

Carla Marchant Santiago; Yerko Monje-Hernández

se inicia al igual que en Ralco, una nutrida historia de contradicciones y enfrentamientos de las comunidades habitantes de los territorios aledaños, la que nuevamente estaría caracterizada por una identidad y pertenencia mapuche. El tema en cuestión, además de las dudas sobre las reales expectativas de desarrollo que podría cumplir el afán forestal, fue la alta toxicidad del proceso de blanqueado y cómo serían liberados los derechos de la producción.

Como indica Monje-Hernández (2020) a pesar de que distintos organismos y documentos como la Resolución de Calidad Ambiental - RCA no otorgaron un permiso de funcionamiento de manera precisa por lo anteriormente mencionado, el afán de los operadores políticos estaba concentrado en la puesta en marcha de la empresa, justificada en el empobrecimiento y crisis económica que vivía la zona. Ante el conflicto de la descarga de residuos, la empresa y gobierno acordaron la siguiente solución:

Se le entregaba el permiso ambiental bajo la condición de descargar sus RILES al mar. La única salida cercana al mar es la Bahía Maiquillahue, el pueblo de Mehuín, localidad de pescadores artesanales y comunidades mapuche costeras. Durante tres años (1996-1998) la empresa y el gobierno no logran entrar a esta zona costera debido a la resistencia de las organizaciones ciudadanas, ecologistas, indígenas, campesinas y particularmente de los habitantes de la localidad misma de Mehuín, que se movilizan incansablemente en defensa de sus derechos socio ambientales. Finalmente, en octubre de 1998 el gobierno acuerda con la empresa que presentara una nueva alternativa de verter los residuos nuevamente en el Río Cruces, pero incorporando ahora mayor tecnología con tratamiento terciario. (Cuenca 2005)

Tras ese acuerdo, la planta comenzó su funcionamiento en 2004, si bien los residuos vertidos en el Río Cruces debían ser tratados con nuevas tecnologías, al parecer no fue suficiente. Un primer episodio de conflicto estuvo centrado en los malos olores que emanaba la planta, y que podían ser percibidos hasta Valdivia distante a más de $50 \mathrm{~km}$ del proyecto, lo que ocasionó que la iniciativa fuera clausurada por mandato de la Comisión Regional del Medio Ambiente (COREMA). Un segundo episodio central en la historia de este conflicto fue que tras el reinicio de actividades y vertimiento de RILES en el Río Cruces, se produjo en 2005 una masiva muerte de cisnes en el Santuario de la Naturaleza Carlos Anwandter (Escaida et al. 2014).

Luego de ese episodio, se inició una nueva etapa del conflicto ambiental, que no solo involucró a las comunidades aledañas al proyecto de CELCO en la comuna de Mariquina, sino que rápidamente se trasladaría a la capital provincial Valdivia. Con la agudización de este conflicto socioambiental se articuló el Movimiento de Acción por los Cisnes, de carácter ciudadano, que veló por la defensa del territorio y sus especies, asociando la mortandad de la especie con los cambios que generó esta actividad y sus residuos en la biota, información que con los años fue confirmada. Este conflicto marcó un importante ante- 
Espacio y territorio como categorías para la comprensión del tiempo presente...

Carla Marchant Santiago; Yerko Monje-Hernández

cedente en la articulación de sectores más amplios de la ciudadanía ante estos episodios, que paulatinamente instalarían las demandas medioambientales en la agenda política de gobernantes locales y nacionales. Además, cabe destacar como un conflicto que surge en espacios marginales como la ruralidad, tiene una escala de expresión que trasciende, y alcanza notoriedad en el radio urbano, situación que no será extraña en conflictos posteriores, donde se instalarán movimientos no acotados solo al territorio intervenido, sino que serán de carácter nacional, tal como fue Patagonia sin Represas.

\subsection{El movimiento social contra el proyecto HidroAysén. La defensa del territorio como agenda de movilización nacional}

Un episodio crucial en la historia reciente de los conflictos socioambientales en Chile fue el movimiento ciudadano contra la instalación de HidroAysén, poniendo en entredicho nuevamente un proyecto de carácter energético, que, de cierta manera, rememoraba la historia del conflicto de Ralco, y ponía en la palestra nuevamente las contradicciones y externalidades de la instalación de hidroeléctricas en el territorio nacional.

Este proyecto, a decir de Romero-Toledo (2014), pretendía construir cinco centrales hidroeléctricas en los ríos Baker y Pascua en la Patagonia occidental en la región de Aysén. Para la realización de este proyecto, se contempló la inundación de 5.919 hectáreas. Esta iniciativa era una inversión mixta entre las transnacionales ENDESA/ENEL y la privada chilena COLBÚN, cuya sociedad se constituye en 2006. Además de las implicancias directas sobre el territorio que sería intervenido, en paralelo se planteó un proyecto de carretera energética, lo que conllevaría la construcción de una de las líneas de trasmisión más larga del mundo con 2.200 kilómetros de largo (Rodrigo y Orrego en Romero-Toledo 2014).

Ante la magnitud de la intervención planteada, tempranamente este proyecto comenzó a generar un rechazo y sospecha en la sociedad chilena, que venía alarmada ante otras experiencias como la central hidroeléctrica Ralco y CELCO en Mariquina. Ante la aprobación del proyecto en 2011 por parte de la Comisión de Evaluación Ambiental de Aysén, HidroAysén se negó a cumplir varias de las condiciones indicadas por las autoridades regionales que versaban sobre auditorías ambientales independientes, baja de un 50\% de tarifas de electricidad de Aysén y la tala completa de los terrenos inundados para evitar emisiones de CO2 (Romero-Toledo 2014). Ante tal situación, el descontento ciudadano se hizo evidente, con un rechazo superior al 61\% en la Encuesta IPSOS de 2011, que en mayo llegaría al 74\%. En mayo y junio se iniciarían importantes ciclos de protesta a nivel nacional, instalando el movimiento "Patagonia Sin Represas" como un hito en la historia reciente chilena, e inclusive el inicio de un ciclo de movilización masiva a nivel de país, que más tarde tomaría otros repertorios.

Revista de Humanidades de Valparaíso, 2021, No 17, 115-143

(c) (1) (9) CC BY-NC-ND 
Lo interesante de este momento para la reflexión que planteamos en este artículo, es que se instala un movimiento social que supera las dinámicas propias del territorio y espacio en específico, rompiendo con la impronta más local y rural que históricamente había destacado a estos conflictos. Por otra parte, HidroAysén evidenció con fuerza las tensiones del modelo y las dinámicas extractivas sobre los territorios intervenidos y concebidos como espacios económicos, sin una impronta social asociada a los modos y formas de vida históricamente desarrolladas en esos territorios.

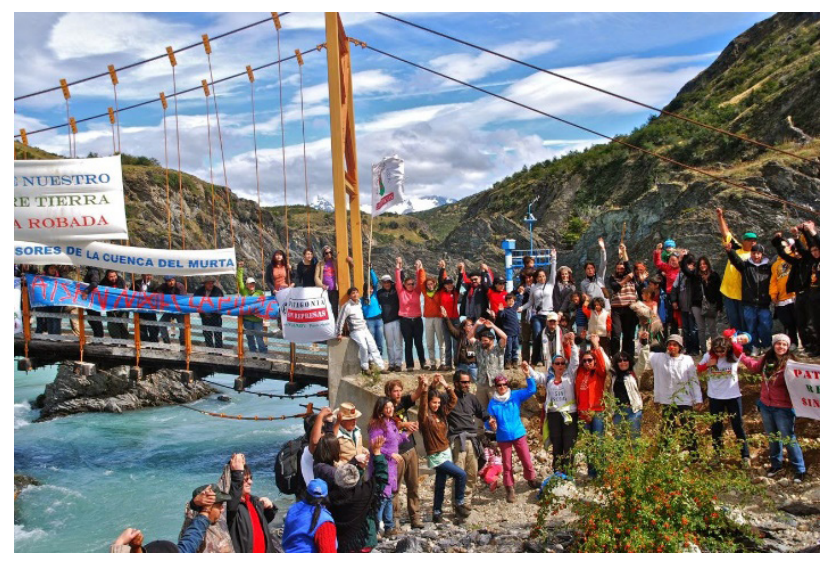

Imagen 1. Protestas contra HidroAysén en Aysén. Fuente: EcoWebtivista.

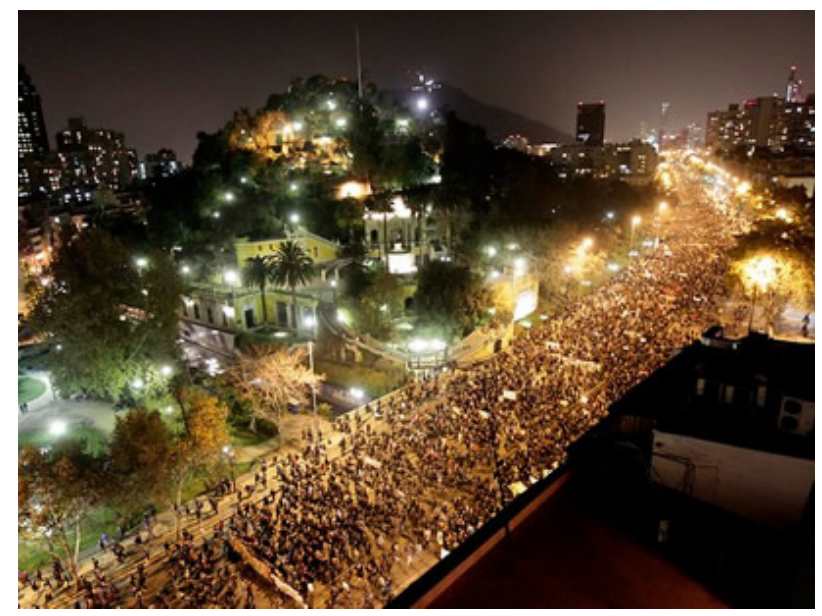

Imagen 2. Protestas contra HidroAysén en Santiago de Chile. Fuente: urbanbox. 
Espacio y territorio como categorías para la comprensión del tiempo presente...

Carla Marchant Santiago; Yerko Monje-Hernández

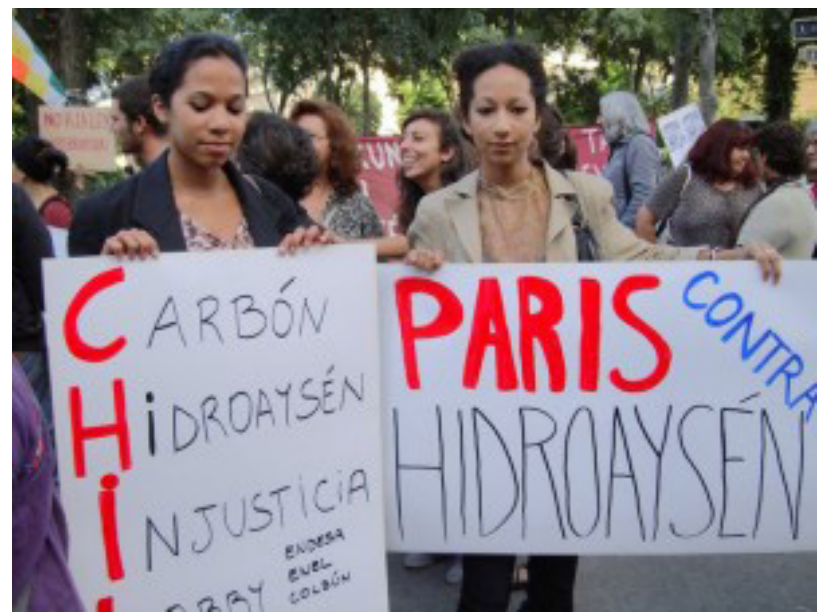

Imagen 3. Protestas contra HidroAysén en París, Francia. Fuente: urbanbox.

Como se presenta en las imágenes uno a tres, el movimiento "Patagonia Sin Represas" se instaló como una agenda de carácter nacional e inclusive internacional. Este momento incluyó una movilización social en las calles a partir del año 2011, que tensionó los discursos y lugares comunes instalados sobre la promesa del desarrollo. Como expresan Romero-Toledo (2014) y Reyes y Rodríguez (2015) esta discusión permeó elementos centrales del debate público como las promesas de desarrollo, lo que se hizo más evidente a un nivel comunicacional. Por ejemplo, desde el propio Proyecto HidroAysén se gestaron campañas con un tenor inquietante, que visualizaban para Chile un complejo panorama energético y productivo de no concretarse la iniciativa, ocupando argumentos inclusive de carácter "ambientalista" con la asociación de la energía hidroeléctrica al agua como recurso renovable y no contaminante. Este discurso tuvo un correlato evidentemente en los propios gobiernos, tanto de Michelle Bachelet como de Sebastián Piñera.

A decir de Reyes y Rodríguez (2015) el movimiento social generado como rechazo a la iniciativa puede ser entendido como una respuesta crucial y emblemática en términos de acción colectiva por su envergadura, ante una problemática de carácter ambiental. Además de la articulación de iniciativas que buscaron concientizar sobre la necesidad de cuidar los recursos naturales, este movimiento consolidó de cierta manera un proceso organizativo por parte de las propias comunidades en espacios como el Consejo de Defensa de la Patagonia (CDP) que reunía a más de 70 organizaciones sociales que compartían la visión del territorio de Aysén como una "reserva de vida". Lo anterior, potenciado con una asociación con otras organizaciones de carácter nacional e internacional, que abrazaron la bandera de la defensa de los territorios frente a un avance de una economía global que profundiza las contradicciones entre sociedad y naturaleza.

De esta manera, el movimiento de Patagonia sin Represas, instaló discusiones que superaron elementos asociados solamente al proyecto referido. Así se instalaron paulati- 
Espacio y territorio como categorías para la comprensión del tiempo presente...

Carla Marchant Santiago; Yerko Monje-Hernández

namente en el debate público discusiones como la necesidad de que el agua sea declarada un bien de uso público y no entregada a la lógica de acumulación privada, la necesidad de políticas de desarrollo sustentable y la consolidación de una institucionalidad ambiental vinculante y realmente efectiva. A esto se añade que este movimiento es parte de un ciclo mayor, que no solo incluye las demandas por la defensa de los territorios, sino que evidencia otras demandas, por ejemplo en educación, teniendo en común la interpelación a la impronta neoliberal en la gestión y regulación estatal.

Finalmente, tras largos años de debates y una creciente judicialización del conflicto que incluía recursos de protección y denuncias en instancias internacionales - el anuncio por parte de ENDESA y Colbún del congelamiento y abandono del afán por el proyecto en 2017, representó un momento crucial para comprender la importancia del espacio y territorio en las dinámicas políticas y sociales contemporáneas. Este movimiento fue presentado por las organizaciones sociales como la principal causa socioambiental de la historia chilena (derechoalagua.cl) y la decisión de frenar el proyecto por parte del consorcio, sería, por tanto, una de las principales victorias.

Es en este marco de debate, es imperioso vislumbrar y complejizar los propios discursos que existen acerca de la naturaleza, ya que el afán de conservación no está exento de dinámicas propias del neoliberalismo. Pero más allá de esa discusión, es innegable que HidroAysén marcaría pauta en otros episodios de conflictos socioambientales de la historia reciente chilena como Punta de Choros, Quintero, Pascua Lama y Chiloé, que evidenciaron con mayor fuerza aún las contradicciones del modelo, especialmente con la denuncia de zonas de sacrificios y dinámicas extractivas que continuaban profundizándose en los distintos territorios. De cierta manera, HidroAysén y el movimiento social generado, fueron un punto crucial para comprender la consolidación de una demanda que parece hoy muy obvia en las movilizaciones nacionales: la defensa de los territorios. En este sentido, creemos que éstas están vinculadas a este giro territorial que ha permeado a las Ciencias Sociales.

\section{Sobre el territorio y la espacialidad desde el despertar social de octubre de 2019}

Si revisitamos el movimiento de octubre de 2019 a través de los medios y sus íconos asociados, nos daremos cuenta que este tuvo una impronta fundamentalmente urbana, expresada por ejemplo, en la refundación de plazas y grandes marchas en las principales 
Espacio y territorio como categorías para la comprensión del tiempo presente...

Carla Marchant Santiago; Yerko Monje-Hernández

urbes del país ${ }^{4}$. Sin embargo, en medio de este escenario de transformaciones profundas, creemos también necesario señalar que muchas de las demandas que se transformaron en proclamas del 180 tienen su origen en conflictos socioambientales, como los expuestos anteriormente, los que se encarnan en los espacios rurales. Sin embargo, pareciera ser que era necesario un evento de gran magnitud, como el estallido, para que se visibilizaran de manera generalizada, o en los términos propios del estallido, se pusieran "en primera línea". Lo anterior, no es nuevo y se debe sin duda, al marcado carácter urbano de nuestra sociedad; las cifras oficiales del Instituto Nacional de Estadísticas (INE 2018, 8) señalan que en el año 2017 un $87,8 \%$ de la población residía en centros urbanos frente a un $12,2 \%$ que lo hace en el espacio rural.

Sin duda que este enfoque dicotómico del territorio (urbano - rural), el cual ha prevalecido en el desarrollo de políticas públicas en nuestro país, es poco integrador de las diversas complejidades de éste y es una de las causas que han contribuido a la generación de diversos desequilibrios estructurales no resueltos, los que han reaparecido con más fuerza desde el estallido social. Sin embargo, esto no es algo nuevo. Recordemos los efectos de la migración campo - ciudad en la segunda mitad del siglo XX; tras el auge del modelo capitalista y el cambio en los modos de producción de mercancías, la industria que requería mano de obra (principalmente habitantes rurales), fue la principal impulsora del crecimiento urbano inorgánico, del vaciamiento rural y la descampesinización, para luego, bajo la imposición del modelo neoliberal, se produjera la reconfiguración del espacio rural, de la estructura agraria y las relaciones laborales. Esto favoreció el desarrollo de políticas silvo-agropecuarias orientadas al comercio internacional, con el consecuente acaparamiento de tierras, generación de graves conflictos ambientales provocados por las industrias mineras, forestales, acuícolas, entre otras, y un fuerte desincentivo y marginalización del mundo campesino, indígena y de sus organizaciones, bajo una impronta de carácter extractivo (Acosta 2016; Gudynas 2016).

Referente a la trayectoria histórica, es posible identificar a partir de la década del noventa una creciente irrupción de la demanda por la defensa del territorio, expresada en lo que la literatura define fundamentalmente como movimientos socioambientales. Los tres momentos presentados anteriormente, no responden solo a un criterio de azar o mera territorialización del conflicto en el Sur de Chile. De Ralco a HidroAysén podemos vislumbrar cómo la categoría de espacio y territorio se instala en una doble dimensión, a

\footnotetext{
${ }^{4}$ Como un camino fundamental para proyectar este debate, se instala precisamente la comprensión de las propias dinámicas y escenarios de la denuncia en estos centros urbanos. La apropiación del espacio público e inclusive los cambios de nombres dan cuenta de una necesidad de lo que Henri Lefebvre denominó el derecho a la ciudad (Harvey 2014), es decir, un grito y movimiento por recuperar la vida urbana, y para este caso no solo la ciudad, sino - como se acuñó en la protesta a partir de la mano de Víctor Jara -, "el derecho de vivir en paz".
}

Revista de Humanidades de Valparaíso, 2021, No 17, 115-143

(c) $(1)(9)$ CC BY-NC-ND 
Espacio y territorio como categorías para la comprensión del tiempo presente...

Carla Marchant Santiago; Yerko Monje-Hernández

nivel de movilización social, por una parte, y enfoque investigativo por otro. Este recorrido reconoce un cruce de lo local/nacional e histórico/territorial, que ciertamente resultará clave también para comprender el octubre chileno.

Los casos estudiados dan cuenta de un momento de inflexión, pero al mismo tiempo de revitalización en torno a la significación del territorio y la espacialidad. Si consideramos los primeros casos de Ralco y el Santuario del Río Cruces, queda al pendiente profundizar la relación de estas movilizaciones con un imaginario y significaciones espacio territoriales asociadas a una cosmovisión mapuche-huilliche en torno a la defensa del territorio. En este sentido, existe una profunda reflexión y aprendizaje de que el territorio no es solo un espacio económico para la extracción de recursos, sino que es parte constitutiva de la vida social y de las dinámicas ambientales. Lo anterior, se hace evidente en los nuevos movimientos y movilizaciones que levantan esa bandera.

Para el caso del movimiento Patagonia Sin Represas, también existe un momento de inflexión similar al de los casos anteriores; sin embargo, a la luz de las dinámicas históricas, resulta interesante evidenciar que no necesariamente este movimiento ha desencadenado una apuesta "anti mercantil" en torno al espacio y territorio. Como indican Núñez, Aliste, Bello y Astaburuaga (2018) existen dinámicas de apropiación y construcción de "nuevas naturalezas", generadas a partir de un renovado vínculo entre capitalismo y lógicas de conservación. Es así como lo verde, natural y prístino, no necesariamente se articula como un discurso antineoliberal y antiextractivista, sino también como un factor de riqueza, donde la conservación no es neutra, sino profundamente vinculada al capital/ poder (Laurín 2015), donde esa conservación se transforma en negocio a través de la venta de una experiencia y habitar verde. Por lo anterior, es urgente comprender y situar el debate en torno al tiempo y espacio, a partir de las dinámicas sociohistóricas recientes, precisamente para evitar caricaturas o construir marcos interpretativos binarios o poco móviles. Ante todo, se debe comprender que la revolución de octubre está siendo.

Por todo lo anterior, la invisibilización histórica de las problemáticas de los espacios rurales es un elemento clave, que creemos se debe tener en cuenta en el contexto del proceso constituyente que el estallido social abrió, con el objeto de valorar sus propias lógicas socio-productivas, las que no necesariamente se acoplan al modelo neoliberal. Es aquí donde precisamente se hace necesaria y urgente la incorporación reflexiva de las categorías de espacio y territorio, que permitan recoger las múltiples expresiones de estos fenómenos. Por tanto, no responde solo a un interés de saber erudito y academicista, sino desde la propia urgencia social y posibilidad de comprender los fenómenos que acontecen en el presente. 
Espacio y territorio como categorías para la comprensión del tiempo presente...

Carla Marchant Santiago; Yerko Monje-Hernández

\section{Conclusiones}

El actual contexto histórico por el cual transitamos como país, nos emplaza a cuestionar la forma sobre cómo desde las Ciencias Sociales hemos desarrollado nuestras interpretaciones y análisis de todas aquellas problemáticas y desafíos que se plasman en cada territorio. En este sentido, la emergencia de nuevos enfoques teóricos y metodológicos, es necesaria, toda vez que existe además una demanda creciente desde la sociedad por conocimientos diferentes, alternos, democráticos e inclusivos, por lo que creemos relevante considerar estos aspectos en los círculos académicos tradicionales. Si bien en este trabajo nos hemos enfocado en refrendar un nuevo diálogo entre Historia y Geografía para lograr una mejor comprensión de los fenómenos socioterritoriales, es prudente recordar que esta fructífera relación y acercamiento posee una robusta tradición, la que, si bien fue olvidada durante un momento de nuestra historia, hoy renace con mayor intensidad, invitando a la interdisciplina como enfoque para afrontar la complejidad social. Ahora, nos resta dejar instalada una segunda reflexión, esta es la urgencia por desarrollar enfoques metodológicos que permitan una adecuada caracterización de las variables del espacio y del tiempo; en este sentido rescatamos el valor de la hermenéutica como un camino que nos permitirá robustecer nuestros planteamientos.

Finalmente, cabe destacar cómo el movimiento de octubre 2019 permitió ampliar el debate sobre los conflictos socioambientales que se encarnan en los espacios rurales, incorporándolos activamente en las demandas, cabildos y movimientos territoriales, elementos que precisamente recogen gran parte de la discusión presentada. Las demandas por derechos básicos, defensa de los bienes comunes y la resignificación de espacios para la vida, evidentemente encuentran su génesis en la propia historia reciente de Chile. Desde el 18 de octubre, podemos indicar con claridad que los espacios rurales, encuentran un correlato en las dinámicas sociales a partir de las propias críticas al modelo extractivo y neoliberal. Para ello, las plazas y centros de las principales urbes del país se transformarían en escenario privilegiado para materializar y visibilizar las aflicciones de las ruralidades marginadas. En este sentido, resulta de mucho interés considerar el planteamiento de Delamaza (2019), quien nos invita a reflexionar sobre cómo los conflictos socioterritoriales están produciendo consecuencias políticas; en este sentido el autor plantea la emergencia de nuevas formas de politización: nuevos actores en lugares no tradicionales y la ausencia de mediadores tradicionales. Considerando esto, sin duda que en el estallido social de octubre muchos de estos conflictos permitieron mover el cerco más allá de lo que parecía posible. 
Espacio y territorio como categorías para la comprensión del tiempo presente...

Carla Marchant Santiago; Yerko Monje-Hernández

\section{Referencias bibliográficas}

Acosta, A. (2016). Las dependencias del extractivismo. Aportes para un debate incompleto. Actuel Marx/Intervenciones, 20, 123-154.

Agrupación de Ingenieros Forestales por el Bosque Nativo - AIFBN (2011). Informe Nacional, Monitoreo Forestal Independiente en Cuencas Hidrográficas Abastecedoras de Agua de la XIV Región de Los Ríos. Valdivia: ONG Forestales por el Bosque Nativo.

Aliste, E., Folchi, M., Núñez, A. (2018). Discourses of Nature in New Perceptions of the Natural Landscape in Southern Chile. Front. Psychol., 9, 1177. https://doi.org/10.3389/ fpsyg.2018.01177

Aliste, E., Núñez, A. (2015). Las fronteras del discurso geográfico: el tiempo y el espacio en la investigación social. Chungará, 47(2), 287-301. https://dx.doi.org/10.4067/S071773562015005000023

Aliste, E. (2014). Apuntes breves para pensar una Geografía Urbana crítica: reflexiones acerca del seminario ciudad neoliberal. En R. Hidalgo y M. Janoschka (eds.), La ciudad neoliberal. Gentrificación y exclusión en Santiago de Chile, Buenos Aires, Ciudad de México y Madrid (pp. 33-41). Santiago de Chile: Serie Geolibros, Instituto de Geografía, Pontificia Universidad Católica de Chile.

Almonacid, F. (2020). Neoliberalismo y Globalización en la agricultura del Sur de Chile, 19732019. Valparaíso: Ediciones Universitarias de Valparaíso, Pontificia Universidad Católica de Valparaíso.

Aróstegui, J. (2004). La historia vivida. Madrid: Alianza Editorial.

Aurell, J., Balmaceda, C., Burke, P., Soza, F. (2013). Comprender el pasado. Una historia de la escritura y el pensamiento histórico. Madrid: Ediciones Akal.

Blanco-Wells, G. (2019). La vida social de la energía: apuntes para el estudio territorializado de las transiciones energéticas. Sociologías, 21(51), 160-185. https://doi.org/10.1590/151745220215106

Bloch, M. (1996[1949]). Apología para la Historia o el oficio del historiador. México: Fondo de Cultura Económica.

Braudel, F. (2019[1949]). El Mediterráneo y el mundo mediterráneo en la época de Felipe II, vol. I. México: Fondo de Cultura Económica.

Camus, P., Hidalgo, R., Pérez, L., Muñoz, E. (2017). ¡Defendamos Dichato! Bienes comunes y conflicto territorial en los espacios litorales chilenos. Revista de geografia Norte Grande, 68, 105-122. https://dx.doi.org/10.4067/S0718-34022017000300105

Camus, P., Arenas, F., Lagos, M., Romero, A. (2016). Visión histórica de la respuesta a las amenazas naturales en Chile y oportunidades de gestión del riesgo de desastre. Revista de geografia Norte Grande, 64, 9-20. https://dx.doi.org/10.4067/S0718-34022016000200002

Camus, P. (2006) Ambiente, bosques y gestión forestal en Chile. 1541-2005. Santiago: Centro de Investigaciones Diego Barros Arana (Dibam).

Revista de Humanidades de Valparaíso, 2021, No 17, 115-143

(c) $(1)(9)$ CC BY-NC-ND 
Espacio y territorio como categorías para la comprensión del tiempo presente...

Carla Marchant Santiago; Yerko Monje-Hernández

Capel, H. (1971). Schaefer y la nueva geografía. En Fred K. Schaefer, Excepcionalismo en Geografia (pp. 1-40). Barcelona: Universitat de Barcelona. http://www.ub.edu/geocrit/schaefer.htm

Capel, H. (2016). Las ciencias sociales y el estudio del territorio. Biblio3W revista bibliográfica de Geografia y ciencias sociales, 21(1149). https://revistes.ub.edu/index.php/b3w/article/ view/26319

Castells, M. (1997). La Era de la Información: Economía, Sociedad y Cultura. Vol. 2 El Poder de la Identidad. Madrid: Alianza.

Castree, N. (2011). David Harvey. En P. Hubbard \& R. Kitchin (eds.), Key Thinkers on Space and Place (pp. 234-241). London: Sage.

Christaller, W. (1933). Die zentralen Orte in Süddeutschland. Jena: Gustav Fischer.

Contardo, O. (2019) Antes de que fuera octubre. Santiago de Chile: Planeta.

Cuenca, L. (2005). Celulosa Arauco en Valdivia: El desastre ambiental en el Río Cruces, resultado del modelo forestal chileno. En Observatorio Latinoamericano de Conflictos Ambientales - OLCA. Disponible en: http://www.olca.cl/oca/chile/region10/ cisnes152.htm.

Delamaza, G. (2019). Consecuencias políticas de los conflictos socio-territoriales. Hacia una conceptualización pertinente. Revista Austral de Ciencias Sociales, 37, 139-160. https://doi. org/10.4206/rev.austral.cienc.soc.2019.n37-08

De Ramón, A. (1985) Estudio de una Periferia Urbana: Santiago de Chile 1850-1900. Revista Historia, 20, 199-294.

De Ramón, A. (2002) Santiago de Chile: Historia de una Sociedad Urbana. Santiago de Chile: Editorial Catalonia.

Escaida, J., Jaramillo E., Amtmann, C. \& N. Lagos (2014). Crisis Socioambiental: El Humedal del Río Cruces y el Cisne de Cuello Negro. Valdivia: Ediciones Universidad Austral de Chile.

Febvre, L. (1970a[1922]). La Terre et l'evolution humaine: introduction Geógraphique a l'histoire. Paris: Albin Michel.

Febvre, L. (1970b[1953]). Los combates por la historia. Barcelona: Ariel.

Franco, M., Levin, F. (2007). El pasado cercano en clave historiográfica. En M. Franco y F. Levin (eds.), Historia Reciente: Perspectivas y desafios para un campo en construcción (pp. 3166). Buenos Aires: Editorial Paidós.

Foucault, M. (2010). Espacios diferentes. En Michel Foucault, El cuerpo utópico. Las heterotopías (pp. 63-81). Buenos Aires: Ediciones Nueva Visión.

George, P. (2004). Diccionario Akal de Geografía. Madrid: Akal.

Gómez, P. (2006). La asimilación de las ideas de Ratzel y la nueva visión del territorio mexicano. Scripta Nova. Revista electrónica de geografía y ciencias sociales, 10(218/25). http:// www.ub.es/geocrit/sn/sn-218-25.htm

Revista de Humanidades de Valparaíso, 2021, No 17, 115-143

(c) $(1)(9)$ CC BY-NC-ND 
Espacio y territorio como categorías para la comprensión del tiempo presente...

Carla Marchant Santiago; Yerko Monje-Hernández

Gómez, J. (1979). Perspectivas geográficas de un pasado y presente conflictivos a un futuro prometedor. Lurralde investigación y espacio, 2, 7-20. http://www.ingeba.org/lurralde/lurranet/lur02/gome02/02gom.htm

González Miranda, S. (2015). La voz desde lejos. La Triple-Frontera Andina: entre la heterología y la globalización. Andamios, 12(28), 19-41. http://www.scielo.org.mx/scielo.php?scrip$\mathrm{t}=$ sci_arttext\&pid=S1870-00632015000200019\&lng=es\&tlng=es.

Gudynas, E. (2016). Modos de producción y modos de apropiación, una distinción a propósito de los extractivismos. Actuel Marx/ Intervenciones 20, 95-121.

Haesbaert, R. (2010). Regional-Global, dilemas da Região e da regionalização na Geografía contemporânea. Rio de Janeiro: Bertrand.

Hagget, P. (1994). Geografia: una sintesis moderna. Barcelona: Editorial Omega.

Harambour, A. (2019). Soberanias fronterizas. Estados y capital en la colonización de Patagonia (Argentina y Chile, 1830-1922). Valdivia: Ediciones Universidad Austral de Chile.

Harvey, D. (1994). La construcción social del espacio y del tiempo: una teoría relacional. Geographical Review of Japan, 67(2), 126-135.

Harvey, D. (2014). Ciudades Rebeldes. Del derecho de la Ciudad a la Revolución Urbana. Buenos Aires: Ediciones Akal.

Hiernaux, D., Lindón, A. (2006). Tratado de geografía humana. Barcelona: Editorial Anthropos.

Höhl, J. (2018). Hidroelectricidad y pueblos indígenas: un análisis del megaproyecto Ralco en la región Bío Bío, Chile. En Astrid Ulloa \& Hugo Romero (eds.), Agua y disputas territoriales en Chile y Colombia (pp. 297-334). Bogotá: Universidad Nacional de Colombia.

Iggers, G. (2012). La historiografía del siglo XX. Desde la objetividad cientifica al desafio posmoderno. México: Fondo de Cultura Económica.

Illanes, M. (2003). Chile descentrado: formación sociocultural republicana y transición capitalista (1810-1910) Santiago de Chile: Editorial LOM.

Instituto Nacional de Estadísticas INE (2018) Síntesis de Resultados Censo 2017. Disponible en https://www.censo2017.cl/descargas/home/sintesis-de-resultados-censo2017.pdf

Klubock, T. (2012). El trabajo de la naturaleza y la naturaleza del trabajo: historia medioambiental como historia social. En Rodrigo Cordero (ed.), Formas de comprender el presente (pp. 53-80). Santiago: Ediciones Universidad Diego Portales.

Laurín, A. (2015). Los territorios universales del siglo XXI: nueva categoría de la espacialidad (do)minada". Geopolitica (s). Revista sobre estudios de espacio y poder, 6(1), 83-106.

Lefebvre, H. (1974). La Production de l'espace, Paris: Anthropos.

Lefebvre, H. (1969). El derecho a la ciudad. Barcelona: Península.

Lösch, A. (1940). Die Räumliche Ordnung der Wirtschaft. Jena: Gustav Fischer. 
Espacio y territorio como categorías para la comprensión del tiempo presente...

Carla Marchant Santiago; Yerko Monje-Hernández

Martínez, M. (2015). La Industria Forestal en la Región de los Ríos: de la conflictividad ambiental a la social, a partir del caso de Mehuín. 1995-2011. Tesis para optar al título de Profesor de Historia y Ciencias Sociales, Escuela de Historia y Ciencias Sociales, Facultad de Filosofía y Humanidades. Universidad Austral de Chile. Disponible en: http://cybertesis.uach. cl/tesis/uach/2015/ffm385i/doc/ffm385i.pdf

Massey, D. (1985). New directions in Space. En J.D. Gregory (ed.), Social Relations and Spatial Structure (pp. 9-19). London: McMillan.

Mayol, A. (2019). Big Bang. Estallido social 2019. Modelo derrumbado - sociedad rota - política inútil. Santiago de Chile: Catalonia.

Monje-Hernández, Y. (2020). Industria Forestal en el Sur de Chile. Transformaciones en comunidades campesinas de la Región de Los Ríos. (1985-2010). Revista Austral de Ciencias Sociales, 38, 313-336. https://doi.org/10.4206/rev.austral.cienc.soc.2020.n38-16

Moraga, Jorge (2001). Aguas turbias. La central hidroeléctrica Ralco en el Alto Bío Bío. Santiago de Chile: OLCA.

Núñez, A., Aliste, E., Bello, A. (2014). El discurso del desarrollo en Patagonia-Aysén: la conservación y la protección de la naturaleza como dispositivos de una renovada colonización. Chile, siglos XX-XXI. Scripta Nova - Revista Electrónica De Geografia y Ciencias Sociales, 18(493/46), 1-13.

Núñez, A., Aliste, E., Bello, A., Astaburuaga, J. (2019). Eco-extractivismo y los discursos de la naturaleza en Patagonia-Aysén: nuevos imaginarios geográficos y renovados procesos de control territorial. Revista Austral de Ciencias Sociales, 35, 133-153. https://doi. org/10.4206/rev.austral.cienc.soc.2018.n35-09

Ortega-Valcárcel, J. (2000). Los horizontes de la Geografía. Teoría de la Geografía. Barcelona: Ariel.

Palma, K. (2013). Desarrollo Forestal en la Región de Los Ríos. Análisis de la resistencia y el impacto en la comunidad Mapuche Lafkenche en la Bahía de Maiquillahue. 1996-2007. Tesis para optar al título de Profesor de Historia y Ciencias Sociales, Escuela de Historia y Ciencias Sociales, Facultad de Filosofía y Humanidades. Universidad Austral de Chile. Disponible en: http://cybertesis.uach.cl/tesis/uach/2013/ffp171d/doc/ffp171d.pdf

Postigo, J., Blanco, G., Chacón, P. (2015). Las ciencias sociales en la encrucijada: el cambio ambiental global en América Latina y el Caribe. En CICS-UNESCO (eds.), Informe mundial sobre ciencias sociales, 2013: cambios ambientales globales (pp. 166-177). París: Ediciones Unesco. https://unesdoc.unesco.org/ark:/48223/pf0000247158

Quesada, R. (2015). Eliseo Reclús. Geógrafo anarquista. Santiago: Editorial Eleuterio.

Quiroz, R., Narváez, A. (2014). De la loca geografia de Mistral a la geografía militar de Pinochet: el periodo de la institucionalización geográfica en Chile (1889-1979). Revista Geográfica de Valparaiso, 49, 30-54. https:/www.pucv.cl/uuaa/site/docs/20180316/20180316172735 149_3.pdf 
Espacio y territorio como categorías para la comprensión del tiempo presente...

Carla Marchant Santiago; Yerko Monje-Hernández

Raffestin, C. (1986). Econogènese territoriale et territorialité. En F. Auriac \& R. Brunet (eds.), Espaces, jeux et enjeux (pp. 175-185). Paris: Fayard \& Fondation Diderot. https://archive-ouverte.unige.ch/unige:4419

Ramírez, B., López, L. (2015). Espacio, paisaje, región, territorio y lugar: la diversidad en el pensamiento contemporáneo. México: UNAM, Instituto de Geografía.

Reyes, S., Rodríguez, J. (2015). Proyecto Hidroaysén: capitalismo extractivista, regulación estatal y acción colectiva en la Patagonia. Polis, I(40), 439-467. https://dx.doi.org/10.4067/ S0718-65682015000100021

Rojas, A., Sabatini, F., Sepúlveda, C. (2003). Conflictos Ambientales en Chile: aprendizajes y desafíos. Revista Ambiente y Desarrollo - CIPMA, 19(2), 23-30. http://www.cipma.cl/ RAD/2003/2_Rojas-S-S.pdf

Romero-Toledo, H. (2014). Ecología política y represas: elementos para el análisis del Proyecto HidroAysén en la Patagonia chilena. Revista de geografía Norte Grande, 57, 161-175. https://dx.doi.org/10.4067/S0718-34022014000100011

Sábato, H. (2007). Saberes y pasiones del historiador. Apuntes en primera persona. En M. Franco y F. Levin (eds.), Historia reciente: perspectivas y desafios para un campo en construcción (pp. 221-233). Buenos Aires: Editorial Paidós.

Smith, N. (1984). Uneven development. Nature, Capital and the Production of Space. Oxford: Blackwell.

Santos, M. (2000). La naturaleza del espacio. Barcelona: Ariel.

Soja, E. (1989). Postmodern Geographies: The Reassertion of Space in Critical Social Theory. Londres, Nueva York: Verso.

Soja, E. (1980). The Socio-Spatial Dialectic. Annals of the Association of American Geographers, 70(2), 207-225. https://doi.org/10.1111/j.1467-8306.1980.tb01308.x

Tuan, Y.F. (1979). Space and Place: Humanistic Perspective. En S. Gale \& G. Olsson (eds.), Philosophy in Geography (pp. 387-427). https://doi.org/10.1007/978-94-009-9394-5_19

Vargas, G. (2012). Espacio y territorio en el análisis geográfico. Reflexiones, 91(1), 313-326. https://www.redalyc.org/pdf/729/72923937025.pdf

Vico, G. (2006[1725]). Principios de una ciencia nueva en torno a la naturaleza común de las naciones. México: Fondo de Cultura Económica. 
